\title{
Jogos cognitivos em pequenos grupos Contribuições às habilidades cognitivas
}

\author{
Daniela Karine Ramos* \\ Natália Lorenzetti da Rocha**
}

\begin{abstract}
RESUMO: Este trabalho apresenta e discute a intervenção junto a crianças com queixas relacionadas à atenção, utilizando jogos cognitivos em pequenos grupos, com o objetivo de melhorar sua capacidade de atenção e resolução de problemas. Caracteriza-se como pesquisa qualitativa e pauta-se, principalmente, na observação participante. Participaram das intervenções semanais, em grupo, alunos, na faixa etária entre 7 e 11 anos, durante seis meses, uma vez por semana, procedidas dos registros em formulário específico. Os resultados evidenciam melhoras significativas às habilidades cognitivas, em especial, a atenção.
\end{abstract}

Palavras-chave: Cognição. Aprendizagem. Jogos cognitivos. Habilidades sociais.

\section{Cognitive games in small groups Contributions to cognitive abilities}

\begin{abstract}
This study presents and discusses interventions with children who are subject to complaints related to their attention span, by using cognitive games in small groups, with the aim of improving their attention and problem solving capacity. It is characterized as qualitative research and is mainly based on participant observation. Weekly group interventions were carried out on children between 7 and 11 years old, once a week for six months, from
\end{abstract}

* Doutora em Educação, professora do Programa de Pós-Graduação em Educação e do Departamento de Metodologia de Ensino da Universidade Federal de Santa Catarina. Líder do Grupo de Pesquisa Edumídia CNPq/UFSC. Florianópolis/SC - Brasil. E-mail: <dadaniela@gmail.com>.

** Mestranda em Psicologia pela Universidade Federal de Santa Catarina. Está vinculada ao Núcleo de Estudos sobre Psicologia, Migrações e Culturas (NEMPsiC). Integra o grupo de pesquisa "Psicologia, cultura e saúde mental",nalinha"violência etrauma". Florianópolis/SC-Brasil.E-mail:<natalialorenzettirocha@gmail.com>. 
information recorded on a specific form. The results show significant improvements in cognitive abilities, especially attention span.

Keywords: Cognition. Learning. Cognitive games. Social skills.

\section{Juegos cognitivos en pequeños grupos}

\section{Contribuciones a las habilidades cognitivas}

RESUMEN: Este trabajo presenta y discute la intervención entre los niños con quejas relativas a la atención, utilizando juegos cognitivos en pequeños grupos, con el objetivo de mejorar su capacidad de atención y solución de problemas. Se caracteriza como investigación cualitativa y se basa, principalmente, en la observación participante. Participaron en las intervenciones semanales en grupo alumnos en la franja de edad comprendida entre los 7 y los 11 años, durante seis meses, una vez a la semana, y los datos obtenidos se registraron en un formulario específico. Los resultados indican una mejora significativa de las habilidades cognitivas, especialmente la atención.

Palabras clave: Cognición. Aprendizaje. Juegos cognitivos. Habilidades sociales.

\section{Jeux cognitifs en petits groupes}

Contributions pour les habilités cognitives

RÉSUMÉ: Ce travail présente et discute l'intervention auprés d'enfants porteurs de difficultés d'attention, à l'aide de jeux cognitifs en petits groupes, avec pour objectif d'améliorer leur capacité d'attention et la résolution de problémes. Il est caractérisé comme une recherche qualitative et est principalement guidé par une observation participante. Des éléves, d'une tranche d'âge de 7 à 11 ans, ont participé , durant six mois, une fois par semaine, à des interventions, qui ont donné lieu à des registres de formulaires spécifiques. Les résultats ont montré des améliorations significatives des habilités cognitives, en particulier, l'attention.

Mots-clés: Cognition. Apprentissage. Jeux cognitifs. Habilités sociales. 


\section{Introdução}

$\mathrm{E}$ ste trabalho analisa a intervenção realizada com crianças, utilizando jogos cognitivos em pequenos grupos, com o objetivo de melhorar a capacidade de manter a atenção e de resolução de problema, visando repercutir de forma positiva na aprendizagem e no desempenho escolar.

Parte-se do pressuposto que o uso dos jogos contribui para o exercício e o desenvolvimento dos aspectos cognitivos de forma lúdica e prazerosa. O jogo satisfaz as necessidades das crianças, propõe o exercício da interação social e o desenvolvimento de habilidades que contribuem para o desenvolvimento infantil (WANG \& AAMODT, 2012). Isso porque são alternativas para expressão e ação para compreensão e aquisição da linguagem (KISHIMOTO, 2001), ampliam as possibilidades de compreensão dos diferentes papéis sociais e do contexto no qual a criança está inserida (SEBER, 1997), e ultrapassam os limites da manipulação dos objetos que cercam a criança, fazendo com que o universo infantil se amplie. (LEONTIEV, 1994).

A proposição da intervenção com os jogos cognitivos pauta-se em resultados de pesquisas que apontam para contribuições do uso dos jogos no aprimoramento das funções executivas (BOOT et al, 2008; DYE \& BAVELIER, 2010; RIVERO, QUERINO, STARLING-ALVES, 2012; MILLER E ROBERTSON, 2010). Essas funções envolvem uma ampla variedade de habilidades cognitivas que implicam: atenção, seletividade de estímulos, capacidade de abstração, planejamento, flexibilidade de controle mental, autocontrole e memória operacional (LENT, 2013).

Dentre as funções referidas, foca-se nesse trabalho na atenção, considerada fundamental ao processo de aprendizagem, e na resolução de problemas, fortemente relacionada aos desafios propostos nos jogos. Destaca-se, ainda, que a dificuldade para manter a atenção é queixa recorrente entre pais e professores nas escolas. Para tanto, apresentamos os resultados de uma intervenção realizada no Colégio de Aplicação da Universidade [avaliação cega] denominada Atendimento Focal, que ocorreu no contraturrno escolar.

\section{Jogos cognitivos, atenção e resolução de problemas}

Os jogos cognitivos são um conjunto de jogos variados que trabalham aspectos cognitivos, propondo a intersecção entre os conceitos de jogos, diversão e cognição (RAMOS, 2013a). Parte-se do reconhecimento da contribuição que os jogos oferecem ao desenvolvimento infantil e coloca-se ênfase nos aspectos cognitivos. A cognição é entendida nesse contexto como "a aquisição, o armazenamento, a transformação e aplicação 
do conhecimento" (MATLIN, 2004, p. 2), o que envolve uma diversidade de habilidades cognitivas, como atenção, memória, percepção, raciocínio, linguagem e resolução de problemas.

A adjetivação dos jogos como cognitivos considera que eles envolvem fortemente o exercício das habilidades cognitivas. Mesmo que não tenham sido desenvolvidos com o objetivo de trabalhá-las, podem ser utilizados com essa finalidade, uma vez que possuem aspectos desafiantes que prescindem do uso das habilidades cognitivas para atingir o objetivo final (RAMOS, 2013b). Nesse sentido, os jogos podem ser utilizados para o aprimoramento das habilidades cognitivas, pois na interação com eles os jogadores aprendem a lidar com sistemas complexos por meio da experimentação, pela tentativa e erro, exercitando o raciocínio lógico para criar estratégias bem sucedidas, visando à superação de desafios e obstáculos (PRESKY, 2010).

Dentre as habilidades cognitivas que podem ser exercitadas a partir do uso de jogos, destacamos a resolução de problemas, utilizada quando se pretende atingir um objetivo, porém não há a solução, e envolve três componentes principais: o estado inicial (situação anterior a resolução), o estado meta (objetivo relacionado a resolução do problema) e os obstáculos (restrições e dificuldades) (MATLIN, 2004). Há vários aspectos cognitivos envolvidos na resolução de problemas, como a atenção, a memória e a tomada de decisões. Essa capacidade é abordada, principalmente, durante a resolução dos desafios e envolvem a identificação do problema, a criação de hipóteses e de estratégias para solução.

Ao mesmo tempo, jogar supõe o exercício de manter a atenção no que se esta fazendo. Assim, destaca-se que "prestar atenção é focalizar a consciência, concentrando os processos mentais em uma única tarefa principal e colocando as demais em segundo plano" (LENT, 2005, p. 579). Tal ação só se torna possível devido à sensibilização seletiva de um conjunto de regiões cerebrais que executa a tarefa principal, inibindo as demais regiões. A atenção refere-se ainda ao "ato de preparar-se para receber informações" (MATLIN, 2004, p. 35).

Conforme Lent (2005) afirma, a atenção possui dois aspectos fundamentais: o de criar um estado de sensibilização (conhecido como alerta) e o de focalizar tal estado de sensibilização em processos mentais e neurobiológicos (a atenção propriamente dita). Assim, pode-se focar a atenção em estímulos sensoriais- um barulho que vem da rua, por exemplo - ou em um processo mental - como um cálculo matemático.

Em relação ao uso dos jogos para o exercício da atenção, Michel e Mateer (2006) reforçam, por meio de seus estudos, que a atenção é uma habilidade que pode ser treinada. A partir disso, Cantiere et al. (2012) desenvolveram um programa de intervenção para treino de habilidades de atenção, utilizando jogos como tangram, sete erros, construção de blocos, dominó, sudoku, jogo da memória, caça palavras, entre outros. Ao final 
os resultados indicaram que o treino a partir desses jogos colaborava para o desenvolvimento das crianças e adolescentes com sinais de desatenção e hiperatividade.

Miller e Robertson (2010), através de um estudo realizado com 71 crianças, entre 10 e 11 anos, organizados em três grupos distintos, dois jogaram jogos parecidos por 20 minutos, diariamente, por 10 semanas e o terceiro grupo não foi submetido às sessões, por meio da aplicação de testes antes e depois, identificaram ganhos significativos, principalmente, nos grupos que participaram da atividade com jogos, tanto na precisão como na rapidez na realização de cálculos.

De maneira similar, Dye \& Bavelier (2010) desenvolveram um estudo com 114 crianças de 7 a 17 anos e 47 adultos, no qual testaram aspectos da atenção visual. A partir dos testes observaram que os jogadores de games de ação tiveram um melhor desempenho em todos os aspectos da atenção testados.

Esses estudos sugerem a transferência de aspectos aprendidos dentro do jogo para a vida diária de um indivíduo e faz-nos refletir acerca da eficiência decorrente do uso de jogos cognitivos em um contexto escolar, onde a atenção é primordial para que se obtenha a aprendizagem dos conteúdos. Esse aspecto é reforçado por Rivero, Querino e Starling-Alves (2012), que, a partir de uma revisão sistemática, descrevem que os jogos são mais atrativos, divertidos e, por apresentarem um sistema de recompensa efetivo, provocam reações positivas nas crianças, facilitando o trabalho com as mesmas.

\section{O método}

O estudo caracteriza-se como exploratório, por procurar ampliar a compreensão sobre o tema, explicitando os aspectos da situação investigada (MALHEIROS, 2011), e utiliza uma abordagem qualitativa, pautando-se, principalmente, na observação participante e na descrição, partindo da noção da realidade como algo dinâmico e voltando-se para o ambiente natural, a partir do qual são extraídos os dados para análise (GODOY, 1995).

A pesquisa toma como objeto de investigação das atividades desenvolvidas [avaliação cega] no Colégio [avaliação cega] com alunos do ensino fundamental (anos iniciais), indicados pelos professores para participar da atividade por apresentarem alguma queixa relacionada à atenção.

As atividades começaram ainda no primeiro semestre de 2013 e foram realizadas por um período de seis meses. Inicialmente, foram indicados e participaram do atendimento focal 12 alunos, porém apenas sete seguiram até o final. Os resultados consideraram a participação desses alunos que têm idade entre 7 e 11 anos.

A pesquisa foi submetida e aprovada no Comitê de Ética, por meio do Parecer 200.436. E observando os procedimentos éticos, todas os responsáveis pelas crianças participantes assinaram o Termo de Consentimento Livre e Esclarecido (TCLE). 


\section{Participantes}

Os participantes, em sua maioria, eram atendidos em trios e em duplas, organizados e mantidos durante os atendimentos, para que pudessem exercitar, além da atenção, habilidades emocionais e sociais (RAMOS et al, 2013), a partir da interação e colaboração entre eles e o mediador.

No quadro a seguir pontuamos a queixa principal descrita pelas professoras, por meio da realização de uma entrevista inicial, e os comportamentos observados nos primeiros atendimentos pelos mediadores.

\section{Quadro 1 - Caracterização inicial dos participantes}

\begin{tabular}{|c|c|c|c|}
\hline Participantes & Idade & Queixa principal & $\begin{array}{l}\text { Comportamentos observados } \\
\text { nos primeiros atendimentos }\end{array}$ \\
\hline Participante 1 & $\begin{array}{l}7 \\
\text { anos }\end{array}$ & $\begin{array}{l}\text { Falta de atenção, } \\
\text { dificuldades para } \\
\text { interagir socialmente, } \\
\text { hiperatividade, } \\
\text { baixo desempenho } \\
\text { nas avaliações feitas } \\
\text { em sala. Possui } \\
\text { diagnóstico de TDAH. }\end{array}$ & $\begin{array}{l}\text { Necessidade de se movimentar } \\
\text { fisicamente, distração, dificuldade } \\
\text { para seguir regras para ter } \\
\text { relacionamento social e para manter } \\
\text { o foco no que está fazendo. }\end{array}$ \\
\hline Participante 2 & $\begin{array}{l}7 \\
\text { anos }\end{array}$ & $\begin{array}{l}\text { Distração, } \\
\text { dificuldades de } \\
\text { organização espacial e } \\
\text { motricidade. }\end{array}$ & $\begin{array}{l}\text { Distração em determinados } \\
\text { momentos, espontaneidade e } \\
\text { pró-atividade. Expressava-se } \\
\text { verbalmente com facilidade, } \\
\text { mostrou-se empático com a } \\
\text { mediadora e os demais colegas. }\end{array}$ \\
\hline Participante 3 & $\begin{array}{l}7 \\
\text { anos }\end{array}$ & $\begin{array}{l}\text { Distração, } \\
\text { dificuldades de } \\
\text { relacionamento } \\
\text { interpessoal e } \\
\text { resolução de } \\
\text { problemas. É bastante } \\
\text { competitivo em sala } \\
\text { de aula. }\end{array}$ & $\begin{array}{l}\text { Dificuldades de concentração e } \\
\text { desmotivação com boa parte das } \\
\text { atividades propostas. Demonstrou } \\
\text { impaciência para esperar sua vez. } \\
\text { Necessitava de atenção maior da } \\
\text { mediadora para a resolução dos } \\
\text { desafios. }\end{array}$ \\
\hline Participante 4 & $\begin{array}{l}10 \\
\text { anos }\end{array}$ & $\begin{array}{l}\text { Distração e falta de } \\
\text { atenção. }\end{array}$ & $\begin{array}{l}\text { Leve dificuldade na manutenção } \\
\text { da atenção durante as atividades } \\
\text { propostas, resposta de reação lenta, } \\
\text { manifestação freqüente de distração } \\
\text { e pouca interação com o colega. }\end{array}$ \\
\hline
\end{tabular}




\begin{tabular}{|c|c|c|c|}
\hline Participantes & Idade & Queixa principal & $\begin{array}{l}\text { Comportamentos observados } \\
\text { nos primeiros atendimentos }\end{array}$ \\
\hline Participante 5 & $\begin{array}{l}11 \\
\text { anos }\end{array}$ & $\begin{array}{l}\text { Falta de interação } \\
\text { social, distração. }\end{array}$ & $\begin{array}{l}\text { Pouca socialização e repertórios de } \\
\text { habilidades sociais insatisfatórios } \\
\text { (se mostrava exigente e controlador } \\
\text { com os colegas). Freqüentemente } \\
\text { manifestava irritação e distração, } \\
\text { tinha dificuldade em manter a } \\
\text { atenção, demonstrava pouca } \\
\text { persistência e motivação nos jogos. }\end{array}$ \\
\hline Participante 6 & $\begin{array}{l}7 \\
\text { anos }\end{array}$ & $\begin{array}{l}\text { Dificuldade de } \\
\text { interação, não } \\
\text { mantém o foco no } \\
\text { que é falado pela } \\
\text { professora e colegas } \\
\text { em sala de aula. }\end{array}$ & $\begin{array}{l}\text { Dificuldade para se manter atento } \\
\text { ao que era falado pelas mediadoras } \\
\text { e colegas, não conseguia se } \\
\text { expressar ou falar sobre suas } \\
\text { vontades. Manifestava distração em } \\
\text { determinados jogos. }\end{array}$ \\
\hline Participante 7 & $\begin{array}{l}7 \\
\text { anos }\end{array}$ & $\begin{array}{l}\text { Distração, dificuldade } \\
\text { para aceitar a opinião } \\
\text { dos outros. }\end{array}$ & $\begin{array}{l}\text { Dificuldade de concentração e de } \\
\text { manutenção da atenção durante } \\
\text { os jogos, pouca abertura para a } \\
\text { opinião e vontade alheia. }\end{array}$ \\
\hline
\end{tabular}

\section{a) Instrumentos}

O estudo pautou-se fundamentalmente na observação e registro dos atendimentos realizados e comportamentos das crianças. Alguns instrumentos foram fundamentais para a pesquisa como: o planejamento dos atendimentos, os jogos cognitivos, o formulário de registro dos atendimentos e as devolutivas sistematizadas.

O planejamento dos atendimentos foi realizado com base nos atendimentos anteriores (suas observações e registros) e nas discussões com a equipe do [avaliação cega] durante as reuniões periódicas. Fazia parte desta etapa, ainda, a seleção prévia dos jogos a serem utilizados e a organização do espaço.

Ao longo dos atendimentos foram utilizados inúmeros jogos, alguns com mais frequência em função da relevância para atingir os objetivos relacionados ao aprimoramento da capacidade de atenção e outros, devido ao interesse que os alunos demonstravam. Os jogos de memória, quebra-cabeça, pegavaretas, dominó e damas eram os preferidos e acabaram sendo fundamentais, uma vez que trabalham: a atenção, o raciocínio lógico, a memorização, a percepção espacial, a criatividade, a persistência e a tolerância à frustração. Além disso, esses desafios, por serem jogados em dupla, estimulavam a interação entre os alunos, possibilitando maior repertório nas habilidades sociais (RAMOS et al., 2013).

As intervenções envolviam, ainda, a proposição de desafios cognitivos, como jogos de T, Torre de Hanói, caixinhas e encaixe, pregos etc.. Segundo Ramos (2013a), tais desafios trabalham habilidades como atenção, raciocínio e resolução de problemas, do mesmo modo que oportunizam o exercício da persistência, tolerância à frustração e paciência. 
Quanto ao formulário de registro dos atendimentos, era preenchido on-line, após as intervenções, descrevendo o conteúdo e os principais comportamentos, incluindo interações sociais, dificuldades, desempenho nos jogos e estratégias de resolução.

Esses registros, por sua vez, foram a base para a construção das devolutivas, entregues aos professores e pais. Foram descritos os procedimentos utilizados nas intervenções, a caracterização das crianças, as principais queixas e indicadores observados em relação à melhora dos aspectos relacionados à atenção, à resolução de problemas, interação social e aprendizagem.

\section{b) Procedimentos metodológicos}

Os atendimentos focais ocorriam uma vez por semana, por um período de 50 minutos, principalmente, em grupos de dois a três alunos. A estrutura dos atendimentos foi previamente definida e inspirada na sessão de terapia cognitiva (FRIEDBERG \& MCCLURE, 2004), porém voltada para intervenção no contexto escolar, em grupo e com foco na atenção. A estrutura seguia os seguintes procedimentos: o registro da atenção com o uso de smiles que ilustram níveis de atenção; a revisão dos desafios da semana que são atividades encaminhadas para serem feitas em casa, semanalmente; o estabelecimento da agenda, que inclui os jogos e atividades a serem trabalhadas; o conteúdo da intervenção que compreende as atividades com os jogos; o encaminhamento dos desafios da semana, como caça-palavras, labirintos, sudokus, liga pontos etc., e o momento de feedback, no qual os alunos são convidados a avaliar as atividades, sua participação e atenção, a partir de uma tabela de reforçamento. Essa tabela descrevia alguns comportamentos, avaliados em conjunto; a partir disso, colavam-se smiles verdes, amarelos ou vermelhos.

Os atendimentos foram realizados por bolsistas de pesquisa e extensão que atuam no [avaliação cega], orientado pelo planejamento, pela supervisão do coordenador e discussões realizadas nas reuniões semanais.

Outro procedimento para coleta de dados foi a entrevista com as professoras das crianças participantes, antes e depois da realização dos atendimentos. Inicialmente, a entrevista buscava conhecer e investigar as queixas, dificuldades e aspectos positivos percebidas em sala. Ao final, a entrevista procurou identificar se as professoras observaram mudanças nas crianças em relação à atenção, à resolução de problemas e à aprendizagem.

Nesse trabalho tomamos como objeto de análise e discussão os registros, as devolutivas e a entrevista com os professores. A partir da leitura flutuante, seleção de indicadores e categorias que apontam para mudanças em termos de aprimoramento das habilidades cognitivas.

As principais categorias de análise utilizadas foram:

a. capacidade de resolução de problemas: o que incluía a assertividade na resolução dos desafios dos jogos, as estratégias utilizadas, a rapidez e a persistência; 
b. atenção: referindo-se a capacidade de manter o foco no jogo - considerando a duração e sua qualidade, a observação das regras do jogo e da atividade proposta, a emissão de respostas adequadas durantes as interações e a mediação.

\section{Resultados e discussão}

No decorrer das intervenções foram utilizadas inúmeras estratégias a fim de motivar e instigar os participantes a envolverem-se nas atividades semanais. A organização do espaço, a seleção dos jogos e a utilização de procedimentos, como o registro de atenção e o feedback a partir da tabela de reforçamento, contribuíram para que fossem obtidos resultados positivos, como a melhora da capacidade de manter a atenção e a resolução de problemas. Ademais, quando se compara a caracterização inicial das crianças e a evolução ao longo dos atendimentos, notam-se mudanças relevantes em relação ao seu desenvolvimento nos comportamentos pró-sociais, à manutenção dos níveis de atenção e ao aprimoramento da capacidade de resolução de problemas.

Diante dos principais resultados, esse estudo entra em consonância com Wang e Aamodt (2012), que constataram a capacidade dos jogos de satisfazer a necessidade das crianças, bem como de exercitar a interação social e o desenvolvimento de habilidades que contribuem para o desenvolvimento infantil. A intervenção baseada no uso dos jogos cognitivos conferiu um caráter lúdico e estimulante, uma vez que as crianças, em sua maioria, mostraram-se interessadas pelas atividades. Isso corrobora o que Rivero, Querino e Starling-Alves (2012) encontraram em sua pesquisa sobre jogos, onde mostram que eles são mais atrativos e divertidos, por apresentarem um sistema de recompensa efetivo.

Os resultados apontam mudanças na atenção em todas as crianças participantes: algumas passaram a mantê-la por mais tempo, outras conseguiram ignorar estímulos irrelevantes no ambiente ou conseguiram responder mais assertivamente ao que era solicitado. Essas mudanças podem ser mais bem observadas nos registros do quadro a seguir. 


\section{Quadro 2 - Principais indicadores da atenção dos participantes.}

\begin{tabular}{|c|c|}
\hline Participantes & Indicadores da Atenção \\
\hline Participante 1 & $\begin{array}{l}\text { No decorrer dos atendimentos ao expressar comportamentos de distração } \\
\text { feedback ou era indagado sobre a situação, o que contribuía para torna-lo } \\
\text { mais consciente dos seus comportamentos. Assim, quando o P1 estava } \\
\text { muito agitado ou desconcentrado, ele mesmo passou a verbalizar no } \\
\text { início do encontro seu estado. De modo geral, o P1 tornou-se mais } \\
\text { habilidoso em manter sua atenção por um tempo maior, ainda que } \\
\text { tivesse momentos de distração. A mãe relatou que fazer a tarefa de casa, } \\
\text { após o atendimento, ficou mais tranqüilo já que ele se mostrava muito } \\
\text { mais concentrado. Essa melhoria na manutenção do foco também foi } \\
\text { percebida pela professora em sala, a qual relatou que os comportamentos } \\
\text { de distração diminuiram. }\end{array}$ \\
\hline Participante 2 & $\begin{array}{l}\text { Manteve níveis satisfatórios de atenção ao longo dos atendimentos e aos } \\
\text { poucos foi diminuindo a freqüência de episódios de distração. Mostrou- } \\
\text { se bastante motivado para a resolução dos desafios propostos e isso } \\
\text { contribuía para manutenção da atenção durante os jogos. Foi possível } \\
\text { perceber que quanto mais gostava da atividade proposta, mais se } \\
\text { engajava para a resolução desta e, conseqüentemente, para a manutenção } \\
\text { da atenção. }\end{array}$ \\
\hline Participante 3 & $\begin{array}{l}\text { A manutenção da atenção podia ser relacionada à motivação com o } \\
\text { jogo, ou seja, quanto mais ele gostava da atividade proposta, mais se } \\
\text { motivava e mantinha sua atenção. Entretanto, jogos que não conhecia ou } \\
\text { desafios que não o agradavam faziam com que a atenção fosse diminuída } \\
\text { e episódios de distração fossem constantes. Assim, uma das estratégias } \\
\text { utilizadas foi propor uma atividade e deixar que ele escolhesse a } \\
\text { próxima, caso ficasse atento e mantivesse a persistência na primeira, } \\
\text { realizaria a que ele escolheu depois. Essa intervenção foi fundamental } \\
\text { para um maior número de encontros onde P3 manteve a atenção de } \\
\text { forma satisfatória e conseguiu resolver os desafios dos jogos. }\end{array}$ \\
\hline Participante 4 & $\begin{array}{l}\text { Percebeu-se melhora no seu nível atencional, fazendo com que a atenção } \\
\text { no jogo e no que estava sendo falado se desse de maneira mais contínua. } \\
\text { Desta forma, se no início ele se distraia facilmente com outras coisas fora } \\
\text { do jogo, ao longo do desenvolvimento das intervenções se visualizou } \\
\text { uma evolução em relação a manter-se focado ao que havia sido acordado. } \\
\text { Ainda a respeito da autopercepção em relação à atenção, o P4 aos poucos } \\
\text { foi se mostrando mais competente para avaliar a atenção e passou a } \\
\text { relacionar certas atividades dentro de sala de aula que o deixavam } \\
\text { disperso, como o teatro, por exemplo. }\end{array}$ \\
\hline Participante 5 & $\begin{array}{l}\text { Começou a perceber quando seu nível de atenção diminuía, } \\
\text { verbalizando, o que aponta pra melhor na capacidade de autopercepção } \\
\text { de seu estado atencional. Assim, cada vez que ele percebia que estava se } \\
\text { distraindo, notava-se um esforço grande para cumprir o que havia sido } \\
\text { determinado, como por exemplo, terminar o jogo. Aos poucos a mediação } \\
\text { e a vontade de vencer conduziram-no a cumprir mais frequentemente } \\
\text { as regras do jogo e revelar melhor capacidade de concentração, quando } \\
\text { comparada aos primeiros atendimentos. Essa evolução na questão da } \\
\text { atenção foi notada também pela professora que exemplificou o ocorrido } \\
\text { pela melhora considerável das notas. }\end{array}$ \\
\hline
\end{tabular}




\begin{tabular}{ll}
\hline Participantes & Indicadores da Atenção \\
\hline & $\begin{array}{l}\text { Passou a entender melhor que, algumas vezes, era necessário jogar o que } \\
\text { o outro colega queria e se observou maior esforço para se manter focado } \\
\text { em atividades que não eram suas preferidas. }\end{array}$ \\
& $\begin{array}{l}\text { Outro desafio foi em relação à manutenção da atenção quando um } \\
\text { colega ou mediador falava, o que também era uma queixa da professora. }\end{array}$ \\
Participante 6 & $\begin{array}{l}\text { Foi tentado trabalhar a questão de perceber/notar o outro, do quanto é } \\
\text { importante estar atento quando alguém fala, do quanto é bom ter alguém } \\
\text { para ouvir quando se está falando. Ainda que a intervenção nesse aspecto } \\
\text { tenha contribuído parcialmente, foi possível notar saltos nesse sentido, }\end{array}$ \\
& $\begin{array}{l}\text { uma vez que nos últimos atendimentos o participante mantinha contato } \\
\text { visual com o outro que falava. Entretanto, esse aspecto merece ser mais } \\
\text { trabalhado em atendimentos futuros. }\end{array}$ \\
& $\begin{array}{l}\text { Manifestava, inicialmente, comportamentos de distração e dificuldade } \\
\text { na manutenção da atenção durante a resolução de desafios. Porém, } \\
\text { percebeu-se que quando era colocado para o P7 que ele estava distraído } \\
\text { ou quando era lembrado sobre a tabela de reforçamento o foco e a } \\
\text { manutenção da atenção acabavam sendo mantidos por um tempo maior. } \\
\text { Apesar de no final dos atendimentos ainda ocorrerem distrações, podê- } \\
\text { se notar que o P7 conseguia se organizar melhor e manter sua atenção } \\
\text { quando indagado mais diretamente sobre ela. Dessa forma, houve uma } \\
\text { maior aceitação das regras dos jogos e um salto na qualidade da atenção } \\
\text { destinada aos jogos propostos. }\end{array}$ \\
\hline Participante
\end{tabular}

De modo geral, nas primeiras intervenções, era comum que qualquer ruído ou objeto presente no ambiente despertasse o interesse das crianças e o jogo acabava ficando em segundo plano, principalmente, se fosse um desafio individual ou algo que exigisse empenho maior que o habitual. De acordo com os resultados observados ao final das intervenções, em especial nos participantes 2, 3, 5 e 7, constatou-se maior interesse, aumento na disponibilidade para "prestar atenção" e uma capacidade de manter essa atenção por mais tempo. Ao final dos atendimentos, as crianças participantes tinham mais persistência e isso fazia com que continuassem atentas por período considerável.

Além disso, observou-se que quanto mais interessados e envolvidos nas atividades, melhor era a qualidade e maior o tempo de manutenção da atenção. Esse aspecto pode ser observado, principalmente, nos participantes 2, 3 e 7, por exemplo, uma vez que ficou bem evidente que quando gostavam do jogo demonstravam melhor desempenho em relação à capacidade de manter a atenção. Aspectos relacionados a reações positivas e atenção são destacados por Wang e Aamodt (2012), os quais identificam em suas pesquisas que os jogos ativam sistemas de sinalização cerebral, como a norepinefrina, o que por sua vez facilita mecanismos de aprendizagem nas sinapses celulares e mobiliza os mecanismos de atenção.

A melhora observada nesta pesquisa reforça o estudo de Michel e Mateer (2006), que relatam que a atenção é uma habilidade a ser treinada. Outros estudos sinalizam, ainda, melhora em quadro de TDAH a partir do uso de jogos, como podemos observar na 
pesquisa descrita por Barros (2002), que ressalta que o jogo permite o treino de capacidades deficitárias em crianças hiperativas e, consequentemente, pode conduzir a resultados satisfatórios no desenvolvimento de outras habilidades. Esse aspecto pode ser ilustrado pelo sujeito 1 deste estudo, que possui diagnóstico de TDAH e, com as intervenções, passou a ter mais paciência e melhorou sua interação com os outros participantes, revelando melhoras em suas habilidades, como o planejamento mais focado das ações, maior atenção nas atividades propostas e assertividade ao responder questionamentos.

A atenção como habilidade fundamental para aprendizagem também está envolvida com a capacidade de resolução de problemas, pois é fundamental prestar atenção às informações importantes do problema, discriminando quais são mais relevantes e vão contribuir na resolução (MATLIN, 2004). Nesse sentido, passamos a destacar os indicadores observados relacionados a essa capacidade no quadro a seguir.

\section{Quadro3 - Principais indicadores da capacidade de resolução de problemas.}

\begin{tabular}{ll}
\hline Participantes & Indicadores da capacidade de Resolução de Problemas \\
\hline Participante 1 & $\begin{array}{l}\text { Ao começar a trazer os desafios de casa mostrou crescente capacidade } \\
\text { de resolvê-los, indicando melhora na capacidade de resolução de } \\
\text { problemas. Outro indicativo de melhora surgiu no relato da mãe } \\
\text { que apontou que antes a família tinha que ajudar freqüentemente na } \\
\text { resolução das tarefas, porém com o passar dos encontros o menino } \\
\text { passou a conseguir resolver o dever sozinho, precisando de ajuda com } \\
\text { menos constância. Observou-se ainda aumento na persistência para } \\
\text { resolver desafios presentes nos jogos. Por fim, passou a resolver os } \\
\text { desafios propostos no atendimento, algo que antes lhe causava bastante } \\
\text { ansiedade enquanto não concluía a resolução. }\end{array}$ \\
& $\begin{array}{l}\text { Ao longo dos atendimentos, demonstrou uma melhora significativa no } \\
\text { que se refere à resolução de problemas. Destaca-se que sua motivação } \\
\text { sempre foi peça chave para não desistir dos desafios, apesar de certa } \\
\text { impaciência em algumas situações. P2 manteve crescente o seu nível } \\
\text { de assertividade. Em alguns momentos parecia ansioso para chegar ao } \\
\text { resultado final, mas isso foi sendo trabalhado e houve uma melhora } \\
\text { observável. }\end{array}$ \\
$\begin{array}{l}\text { Po início do atendimento expressou dificuldades para resolver os } \\
\text { desafios. Se distraia com muita facilidade e não tinha muita motivação } \\
\text { para continuar persistindo na resolução dos desafios. Com o passar dos } \\
\text { atendimentos, buscou-se motivá-lo a fim de que conseguisse concluir a } \\
\text { resolução dos desafios. Iniciou-se esse processo com jogos mais simples } \\
\text { e os resultados foram positivos. No final dos atendimentos, o sujeito } \\
\text { já estava conseguindo resolver desafios que antes o angustiavam, } \\
\text { mantendo a motivação e revelando maior persistência. }\end{array}$ \\
Participante
\end{tabular}




\begin{tabular}{|c|c|}
\hline Participantes & Indicadores da capacidade de Resolução de Problemas \\
\hline Participante 4 & $\begin{array}{l}\text { Em momentos onde se sentia pressionado pelo colega a jogar de forma } \\
\text { rápida, manifestava comportamentos impulsivos e não conseguia } \\
\text { acertar ou resolver o que era solicitado, fazendo com que os números } \\
\text { de assertividade diminuíssem bastante. Ao final dos atendimentos os } \\
\text { comentários sobre o desafio da semana mudaram e passou a relatar } \\
\text { que havia resolvido sozinho, bem como conseguia se concentrar mais, } \\
\text { diferentemente do início, em que relatava dificuldades. Gradativamente } \\
\text { com as intervenções houve uma melhora considerável a respeito da } \\
\text { capacidade de persistir em atividades mais desafiadoras. }\end{array}$ \\
\hline Participante 5 & $\begin{array}{l}\text { Demonstrava, nos atendimentos iniciais, pouca persistência em jogos } \\
\text { que exigiam mais atenção, logo perdia sua motivação e a vontade } \\
\text { de continuar tentando. Nos últimos atendimentos, constatou-se um } \\
\text { aumento na persistência e na capacidade de resolução de desafios, pois } \\
\text { demonstrava maior assertividade na resolução dos desafios dos jogos. } \\
\text { A professora se disse muito satisfeita com o resultado alcançado, já } \\
\text { que P5 passou a responder perguntas na sala de aula, principalmente, } \\
\text { questões referentes à matemática, matéria em que antes ele possuía } \\
\text { bastante dificuldade de concentração. }\end{array}$ \\
\hline Participante 6 & $\begin{array}{l}\text { Foi perceptível a evolução na resolução dos desafios propostos, } \\
\text { principalmente, os que eram jogados de forma individual. Apesar de P6 } \\
\text { preferir os jogos que eram em grupo, constantemente conseguia manter } \\
\text { mais a atenção em desafios individuais e, com isso, a persistência e a } \\
\text { capacidade de resolução se davam de maneira mais positiva. }\end{array}$ \\
\hline Participante 7 & $\begin{array}{l}\text { No início, não se mostrava persistente na resolução dos desafios em que } \\
\text { a vitória não viesse com certa facilidade. Gostava de jogar apenas jogos } \\
\text { individuais, quando havia a necessidade de jogar em grupo se mostrava } \\
\text { bastante resistente. Aos poucos, parou de expressar comportamentos } \\
\text { contrários aos jogos em grupo. } \\
\text { Quanto à assertividade esta aumentou consideravelmente quando } \\
\text { se mostrou menos resistente e mais disposto a jogar. A respeito da } \\
\text { agilidade não foi possível perceber melhora. Entretanto, as estratégias } \\
\text { utilizadas para resolução foram se diversificando e o auxiliaram na } \\
\text { resolução dos desafios dos jogos. }\end{array}$ \\
\hline
\end{tabular}

Os registros sistematizados no Quadro 3 permitem observar o desenvolvimento de maior autonomia durante a resolução, em especial, nos participantes 1e 3 que passaram a necessitar de menor mediação para resolver problemas. Outro aspecto que chama a atenção é a manifestação de maior persistência, que pode ser observada na maioria dos participantes 1, 2, 3, 4 e 6. Além disso, algumas crianças tornaram-se mais rápidas na resolução de problemas, como os participantes 4,5 e 6 . 
A melhoria na capacidade de resolução dos desafios e jogos pode ser observada na maioria das crianças. Entretanto, algumas se destacaram mais nesse aspecto, visto que antes possuíam uma dificuldade mais visível. É o caso do sujeito 1, que, além de se mostrar muito disperso e distraído no início dos atendimentos, dificilmente conseguia solucionar um desafio. Mostrava-se impaciente com os jogos, não tinha persistência e acabava distraindo a si e aos colegas que participavam do atendimento em seu horário. Ao longo das intervenções, após serem trabalhadas questões relacionadas à paciência e à importância em planejar a ação para se ganhar o jogo, a criança começou a revelar saltos importantes em seu desenvolvimento. A professora relatou que ela se mostrava mais atenta na sala de aula e a mãe disse que estava mais fácil fazer a tarefa de casa com o filho, já que agora ele possuía maior capacidade de concentração e conseguia resolver os exercícios de forma mais tranquila e ágil, principalmente, os da disciplina de matemática.

Esses resultados fortalecem a investigação de Miller e Robertson (2010) que confirmam que os jogos influenciam na aprendizagem, autopercepção e agilidade na resolução de problemas que envolvem cálculos. Green (2000) também evidencia em seus estudos que os jogos no ambiente escolar contribuem para o aprimoramento das funções executivas, como atenção, concentração, seletividade de estímulos, planejamento, controle mental, autocontrole e memória operacional, fundamentais ao processo de aprendizagem.

É notório que os resultados encontrados em nosso estudo estão em concordância com o que esses autores relatam, já que as crianças em sua maioria melhoraram os níveis de atenção e concentração dentro da sala de aula e obtiveram evolução na resolução de problemas e notas escolares.

Durante as intervenções, através do uso dos jogos cognitivos, as crianças eram constantemente colocadas diante de problemas a serem resolvidos. Assim, era possível perceber que, com os atendimentos, as respostas pararam de ser aleatórias e passou-se a articular e pensar melhor na resolução de determinado desafio, bem como em todos "os passos" necessários para que a resolução do jogo fosse satisfatória. Essa capacidade de planejamento, conforme colocam Krikorian, Bartok e Gay (1994), envolve o estabelecimento de uma estratégia sequencial para que um objetivo possa ser atingido, aspecto fundamental em qualquer tarefa de resolução de problemas, seja no cotidiano, seja no jogo através do aspecto lúdico.

O papel do mediador nessa intervenção também merece ser destacado, uma vez que não se restringia apenas em manter as crianças motivadas e focadas no jogo ou a mediar as relações e interações entre as crianças. Cabia ao mediador auxiliar a criança na identificação de seu progresso e na responsabilidade por sua evolução, além de acompanhá-la em sua compreensão acerca dos estímulos, situações ou momentos em que perdia a atenção. Isso pode ser mais bem explicado por meio do exemplo do que acontecia durante a correção do desafio da semana. Muito mais do que apontar se a criança 
acertou ou não o desafio, o mediador tinha o papel de problematizar o porquê de ela ter acertado ou não. Assim, tentava-se identificar com ela o que poderia ter contribuído para esse acerto e o que poderia ter ajudado para distração e possível não resolução do desafio da semana. Daí pode-se perceber que muitos relatavam, no início, que faziam a tarefa na sala de suas casas com a televisão ligada, outros falavam que faziam junto com todos os membros da família enquanto estavam conversando. A partir daí, as crianças foram identificando lugares onde se sentiam mais a vontade para fazer o desafio da semana e para manter a atenção necessária em sua resolução. Notou-se que quando as crianças identificaram alguns estímulos que as distraiam, passavam a trazer o desafio da semana resolvido e sem queixas quanto à dificuldade.

Além disso, durante o momento de feedback, onde a tabela de reforçamento era utilizada, a intervenção do mediador era fundamental para favorecer a reflexão durante a autoavaliação, e estabelecer considerações a fim de que as percepções das crianças não fossem muito discrepantes daquelas dadas pelos mediadores e seus pares. O papel do mediador durante esse momento era favorecer o autoconhecimento e melhores condições para perceber, por exemplo, sua capacidade e disposição para manter a atenção e, aos poucos, desenvolver mecanismos e estratégias para favorecer sua manutenção. Desta forma, a tabela de reforçamento vai muito além de algo que pune, uma vez que ela foi o meio facilitador para que a autopercepção e o conhecimento do próprio meio fossem dados de forma mais lúdica e interativa com o universo infantil.

Esses resultados indicam que o uso dos jogos cognitivos aliado à mediação e a estratégia utilizada mostraram-se eficazes para provocar mudanças, tanto nos repertórios sociais, quanto nas estratégias cognitivas para a resolução dos desafios, por meio da diversificação das hipóteses de solução, na maior rapidez e maior assertividade na resolução, favorecendo assim o exercício da capacidade de resolução de problemas e da atenção.

Além desses aspectos, a partir das observações e registros, também foi possível observar nas crianças mudanças como:
a. demonstração de mais autocontrole durante as interações sociais e ações relacio- nadas aos jogos;
b. aprimoramento nas habilidades sociais, como paciência para esperar sua vez na jo- gada, respeito ao ritmo e estratégias utilizadas pelos colegas, ausência de deboche ou chacota no momento da vitória;
c. aumento do comprometimento com as atividades desenvolvidas e tarefas encami- nhadas para casa;
d. diminuição do tempo de reação para responder aos estímulos dos jogos; 


\section{Considerações finais}

A utilização de jogos no contexto escolar mostrou-se efetiva para trabalhar questões de aprendizagem e de treinamento de funções executivas por serem parte do cotidiano das crianças e representarem ferramenta lúdica diferenciada daquelas que habitualmente são utilizadas no ambiente escolar. Pôde-se observar, através das intervenções, que a motivação dos alunos é correlacionada diretamente com o fato de gostarem ou não da atividade, fato que sugere que muitas vezes a desatenção em sala de aula pode ser motivada por métodos que não exercitam a ludicidade, dificultando sua compreensão pelo universo infantil.

Além disso, os jogos permitem utilizar diversas estratégias para o aperfeiçoamento de habilidades cognitivas e sociais, pois as regras e os desafios prescindem do uso dessas habilidades. Notou-se que, ao passo em que eram integradas a técnicas de reforçamento, em especial, de forma mediada, geravam um resultado positivo, atuando simultaneamente em diversos fatores relacionados às queixas anteriores. Assim, cabe considerar que a mediação, associada às atividade com jogos, foi uma estratégia bastante efetiva nessa intervenção, pois dava ao sujeito um feedback, permitindo que conhecesse constantemente sua evolução ou então que identificasse o que poderia contribuir para a desatenção.

Como possíveis desdobramentos e indicações de futuras pesquisas, pode-se investigar acerca da influência do método utilizado nos atendimentos, o que pode minimizar os efeitos do uso dos jogos, a prevalência do gênero masculino nesse atendimento, bem como a faixa-etária e o número de sessões, para verificar sua efetividade. Como limitação do estudo, cabe ressaltar que os achados são tomados como fortes indicadores, pois concorrem com o próprio percurso do desenvolvimento infantil e a inserção das crianças no contexto escolar que tendem a repercutir de forma positiva sobre o aprimoramento das habilidades cognitivas.

Por fim, reforçamos que os jogos cognitivos são muito bem-vindos no contexto escolar, uma vez que há fortes indícios de que permitem o exercício da atenção e da resolução de problemas, o aprimoramento das habilidades sociais e funções executivas, contribuindo para a aprendizagem dos alunos de forma lúdica e divertida.

Recebido em 18/11/2015 e aprovado em 15/03/2017 


\section{Referências}

BARROS, Juliana M. G. Jogo infantil e hiperatividade. Rio de Janeiro: Sprint, 2002.

BOOT, Walter R. et al. The effects of video game playing on attention, memory, and executive control. Acta Psychologica, v. 129, n. 3, p. 387-398, nov. 2008.

CANTIERE, Carla N.; et al. Treino cognitivo em crianças e adolescentes com sinais de desatenção e hiperatividade: proposta de protocolo de intervenção neuropsicológica nos domínios verbal e executivo. Cadernos de Pós Graduação em Distúrbios do Desenvolvimento, v. 12, n.1, 98-107, 2012.

DYE, Matthew W.G., BAVELIER, Daphne. Differential development of visual attention skills in schoolage children. Vision Research, v. 50, n.4, 452-459, 2010.

FRIEDBERG, Robert D.; MCCLURE, Jessica M. A prática clínica de terapia cognitiva com crianças e adolescentes. Porto Alegre: Artmed, 2004.

GREEN, Joane. Neuropsychological evaluation of the older adult: A clinician's guidebook. San Diego, CA: Academic Press, 2000.

GODOY, Arilda S. A pesquisa qualitativa e sua utilização em administração de empresas. Revista de Administração de Empresas, 35(4), 65-71, 1995.

KISHIMOTO, Tizuko. O jogo e a educação infantil. In: . Jogo, brinquedo, brincadeira e a educação. 5. ed. São Paulo: Cortez, 2001.

KRIKORIAN, Robert, BARTOK, John \& GAY, Nancy. Tower of London procedure: A standard method and developmental data. Journal of clinical and Experimental Neuropsychology, v. 16, n. 6, 840-850, 1994.

LENT, Roberto. Cognição e funções executivas. IN: LENT, Roberto. Neurociência da mente e do comportamento. (pp. 287-302). Rio de Janeiro: Guanabara Koogan, 2013.

2005.

Cem bilhões de neurônios: conceitos fundamentais de neurociência. São Paulo: Atheneu,

Leontiev, Alexei N. Os principios psicológicos da brincadeira pré-escolar. In: Vygotsky, Lev S.; Luria, Alexander R.; Leontiev, Alexei N. (Orgs.), Linguagem, desenvolvimento e aprendizagem. São Paulo: Moraes, 1994.

MALHEIROS, Bruno T. Metodologia da pesquisa em educação. Rio de Janeiro: LTC, 2011.

MATLIN, Margaret W. Psicologia cognitiva. (5a․ ed.). Rio de Janeiro: LTC, 2004.

MICHEL, Jason A., \& MATEER, C. A. Attention rehabilitation following stroke and traumatic brain injury. A review. Europa medicophysica, v. 42, n. 1, 59-67, 2006.

MILLER, David J.; ROBERTSON, Derek P. Using a games console in the primary classroom: Effects of 'Brain Training' programme on computation and self-esteem. British Journal of Educational Technology, v. 41, n. 2, 242-255, 2010.

PRENSKY, Mark. Não me atrapalhe mãe, eu estou aprendendo. São Paulo: Phorte, 2010.

RAMOS, Daniela K. Jogos cognitivos eletrônicos: contribuições à aprendizagem no contexto escolar. Ciências \& Cognição (UFRJ), v. 18, p. 19-32, 2013a. 
Jogos cognitivos e o exercício de habilidades cognitivas. In: VIDAL, Cristiane D.; ELIAS, Isaque M.; HEBERLE, Viviane M. (Orgs). (Org.). Pesquisas em Games: ideias, projetos e trabalhos. 1ed. Florianópolis: UFSC/LLE/CCE, 2013b, v. 1, p. 118-133.

RAMOS, Daniela K. et al. Jogos e colaboração na escola: alternativas para o exercício de habilidades sociais. In: III Seminário Aulas Conectadas - inovação curricular e aprendizagem colaborativa no ensino básico, 2013, Florianópolis. Caderno de resumos do II Seminário aulas conectadas: inovação curricular e aprendizagem colaborativa no ensino básico. Florianópolis: UDESC, 2013.

RIVERO, Thiago S.; QUIRINO, Emanuel H. G.; STARLING-ALVES, Isabella. Videogame: seu impacto na atenção, percepção e funções executivas. Neuropsicologia Latinoamericana, v. 4, p. 38-47, 2012.

SEBER, Maria da Glória. A importância do jogo no desenvolvimento psicológico da criança. In: SEBER, Maria da Glória; LUÍS, Vera Lúcia. Psicologia do pré-escolar: uma visão construtivista. São Paulo: Moderna, 1997. p. 52-69.

WANG, Sam; AAMODT, Sandra. Play, Stress, and the Learning Brain. Cerebrum, September 24, 2012. Disponível em: http://dana.org/news/cerebrum/detail.aspx?id=39402. Acessado em 25 fev. 2013. 